\title{
A study of the climate change impacts on fluvial flood propagation in the Vietnamese Mekong Delta
}

\author{
P. D. T. Van ${ }^{1,2}$, I. Popescu ${ }^{2}$, A. van Griensven ${ }^{2,5}$, D. P. Solomatine ${ }^{2,3}$, N. H. Trung ${ }^{1}$, and A. Green ${ }^{4}$ \\ ${ }^{1}$ College of Environment and Natural Resources, Can Tho University, Vietnam \\ ${ }^{2}$ UNESCO-IHE Institute for Water Education, Delft, The Netherlands \\ ${ }^{3}$ Water Resources Section, Delft University of Technology, The Netherlands \\ ${ }^{4}$ Mekong River Comission, Phnom Penn, Cambodia \\ ${ }^{5}$ Department of Hydrology and Hydraulic Engineering, Vrije University Brussels, Belgium
}

Correspondence to: I. Popescu (i.popescu@unesco-ihe.org)

Received: 11 May 2012 - Published in Hydrol. Earth Syst. Sci. Discuss.: 8 June 2012

Revised: 7 November 2012 - Accepted: 19 November 2012 - Published: 13 December 2012

\begin{abstract}
The present paper investigated the extent of the flood propagation in the Vietnamese Mekong Delta under different projected flood hydrographs, considering the 2000 flood event (the 20-yr return period event, T. V. H. Le et al., 2007) as the basis for computation. The analysis herein was done to demonstrate the particular complexity of the flood dynamics, which was simulated by the 1-D modelling system ISIS used by the Mekong River Commission. The floods of the year 2050 are simulated using a projected sea level rise of $+30 \mathrm{~cm}$. The future flood hydrograph changes at Kratie, Cambodia, were also applied for the upstream boundary condition by using an adjusted regional climate model. Two future flood hydrographs were applied at the upstream part of the delta, the first one in a scenario of climate change without considering developments in the Mekong Basin, and the second one in a scenario of climate change taking into account future development of the delta. Analyses were done to identify the areas sensitive to floods, considering the uncertainty of the projection of both the upstream and downstream boundary conditions. In addition, due to the rice-dominated culture in the Vietnamese Mekong Delta, possible impacts of floods on the rice-based farming systems were also analysed.
\end{abstract}

\section{Introduction}

Climate change is an on-going process with notable impacts on the eco-hydrological environment (Black and Burns, 2002; Gupta et al., 2002; Prudhomme et al., 2003) leading to significant challenges to the livelihood of local residents in different parts of the world (Lespinas et al., 2009; Muste et al., 2010; Quinn et al., 2010). Vietnam is seen to be one of the most vulnerable countries to global climate change impacts, and the Vietnamese Mekong Delta (VMD) (Fig. 1) is identified as particularly susceptible to the impacts of extreme climate events and climate variability (ADB, 2009; WWF, 2009). Possible changes of the hydrological conditions (including spatial and temporal distribution of floods, modification of wet and dry season precipitation and alteration of salinity intrusion pattern) as a consequence of the global climate change may present significant threats to the socioeconomic and environmental systems (Quinn et al., 2010).

Hoanh et al. (2010) conducted a study to explore the possible impacts of both the climate change and the economic development on the flow regimes of the Mekong and its delta. The study concluded that, given the above mentioned conditions, there could be a possible increase of flooding events during wet season, while there will be more periods of water shortage in the dry season. The maximum monthly flow, on the Mekong river is estimated to increase by 35 to $41 \%$, and by 16 to $19 \%$ in the delta, with lower values estimated for the years 2010 to 2038 and higher values for the 2070 to 2099 (Hoanh et al., 2010; Västilä et al., 2010). The same studies estimate a decline in the minimum monthly flows, by 17 to $24 \%$ in the basin, and by 26 to $29 \%$ in the delta. As a consequence, expansion of areas under severe water stress (flood and drought) would be one of the most pressing environmental problems in the Mekong basin and the delta, as 


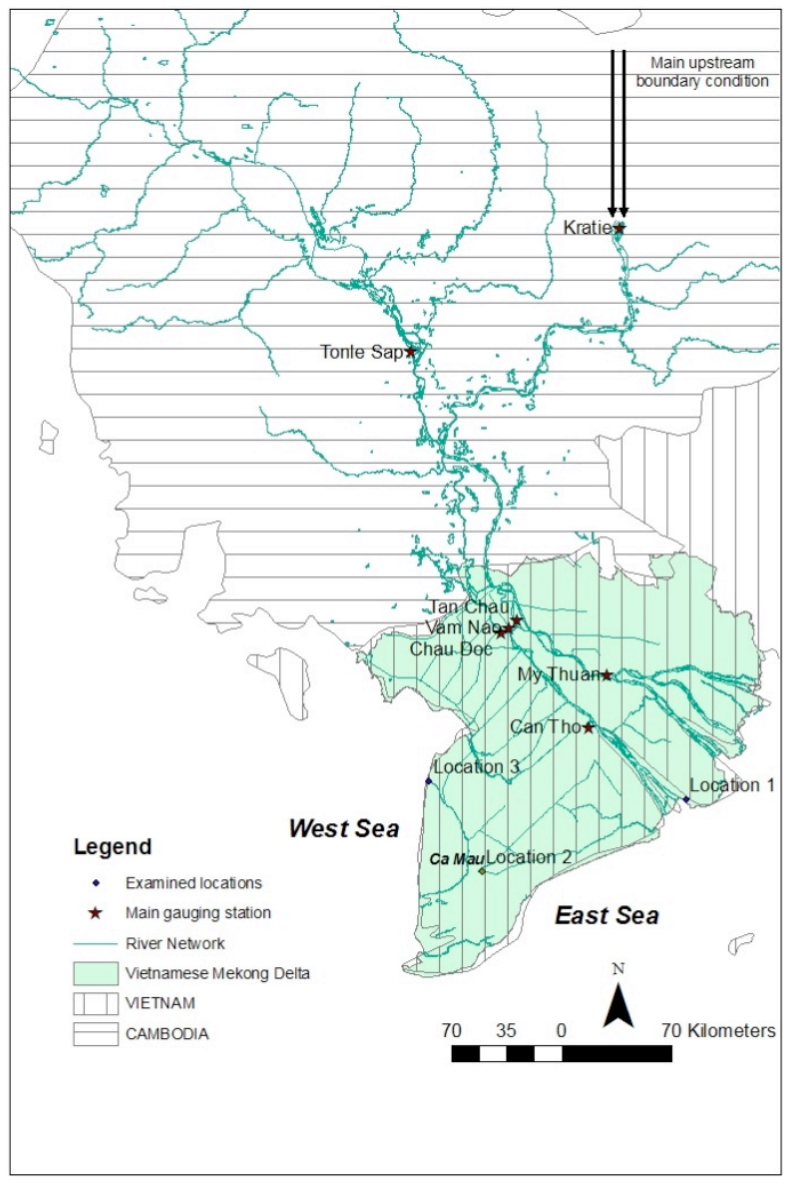

Fig. 1. Mekong river network and the Vietnamese Mekong Delta.

the number of people living in the area is likely to increase substantially.

One of the major impacts of the climate change is expected to be the sea level rise (SLR). The SLR in the West and East Seas were defined by the Vietnamese Ministry of Natural Resources and Environment (MONRE). Looking at the SLR predictions for 2050, as compared with the 2000 situation, this might result in a large inundated area of the VMD mainly along the east and west coast of the delta (WWF, 2009), leading to significant loss of mangrove forest and agricultural lands, while the livelihoods of about 1.9 million local residents will be at risk (Ericson et al., 2006).

Studies of the modifications of the water balance within the Mekong basin and delta, combined with sea level rise, show that this would result in great alteration of the ecohydrological environment (Lu and Siew, 2006), and consequently, to adverse impacts on the socio-economic system would be felt in the VMD. In fact, the modification of the upstream discharge would be the main concern for the upstream section of the VMD (Västilä et al., 2010; Dinh et al., 2012), while the rise of the sea level resulting in wider (temporal) inundation along the coast, is important for the downstream section (Carew-Reid, 2008). Apart from the significant changes on the livelihood of the local residents (Nuorteva et al., 2010), the sea level rise would contribute to changes of the hydraulic nature along the river network (Dooge and Napiorkowski, 1987).

A number of studies were conducted to project the impacts of changes of the upstream discharge and the sea level rise on the VMD with specific attention to the inundation in the upstream section of the VMD (e.g. Wassmann et al., 2004; Le et al., 2007, 2008; Dinh et al., 2012). It was found that the impacts of projected climate change would be an expansion of the inundation area towards the sea (Wassmann et al., 2004; Dinh et al., 2012), and the average and maximum water levels, as well as the flood duration will increase in the period 2010-2049 (Västilä et al., 2010). Johnson and Kummu (2011) make an extensive review of the available models currently applied in the Mekong Basin. These models are all based on 1-D Saint Venant equations, are using both commercial (e.g. ISIS, Mike 11) and non-commercial developed software tools (i.e. Vietnam River Systems and Plains (VRSAP)) and are used to study the flood situation in the VMD. However, these studies did not consider either the modification of the flood dynamics in the delta after the hydrograph upstream changes in combination with sea level rise or the river triggered floods of short duration, which are affecting the coastal area of Vietnam (i.e. the downstream section of the VMD). In addition, detailed inundation modelling and mapping of the VMD floods of short duration should be addressed as well because of their significant impacts on farming.

The present study is looking into the temporal and spatial dynamics of the fluvial flooding of the whole VMD in cases of short duration events. The study uses the 1-dimensional hydrodynamic model ISIS provided by the Mekong River Commission (MRC). The model is validated for the flood event of the year 2000 (a short flood event), and based on it, we investigate possible impacts of climate change on the flood dynamics (e.g. inundation extent and temporal variation) considering the combined effects of predicted changes of the upstream flow and sea level rise. There are two main drivers for the changes of the upstream flow of the Mekong: the climate change, and the hydropower and irrigation developments that are planned to take place in the near future.

Some analysis of sensitivity of the model results to different boundary conditions is presented in this paper; however, detailed uncertainty analysis of the inundation pattern resulting from the hydrodynamic model is the focus of a separate analysis that is currently in preparation and will be reported in a subsequent publication.

It is important to mention that the study is focused only on the fluvial floods generated by the SLR, and does not consider the floods due to coastal phenomena such as surges, which are occurring on an elevated sea level. In addition, pluvial floods are also not considered because they do occur occasionally and lead to local effects that are less significant than the fluvial ones. 


\subsection{The study area}

According to the Mekong River Commission (MRC) (MRC, 2007), the Mekong Delta begins at Phnom Penh, Cambodia, where the river divides into two main branches, the Mekong and the Bassac (Fig. 1). In Vietnam, the Mekong Delta is relatively flat (generally, the average land surface elevation is not greater than $5.0 \mathrm{~m}$ above the mean sea level (m a.s.l.)) and the complex channel network forming the delta has been modified over a long period of time due to agricultural activities and residential developments.

The VMD river network is fluvially unstable (Reichel and Nachtnebel, 1994; Neuhold et al., 2009; MRC, 2010a) and the hydraulic nature of it is highly complex, impacted by both the upstream discharge and sea level along the East and West Seas. The East and West Seas have semidiurnal and diurnal tides, respectively (Nguyen and Savenije, 2006) (Fig. 2a and b). The tidal amplitude from the East Sea is between 3.0 and $3.5 \mathrm{~m}$ a.s.l., resulting in significant daily water level variations, especially during the dry season when the river stage is strongly driven by the tidal regimes. For example, at Can Tho (90 km upstream from the sea), the daily variations of the river water level are of about 1.5 to $2.0 \mathrm{~m}$, and at Tan Chau and Chau Doc (190 km upstream from the coast), the variations are of approximately $1.0 \mathrm{~m}$. In Fig. 3a the maximum measured daily discharge in 2000 is presented for two main upstream gauging stations in the VMD (Tan Chau and Chau Doc). The discharge entering the VMD is routed along the Mekong branch and then the flow is divided between the Mekong branch and the Vam Nao canal, which routes part of the water to the Bassac branch of the delta.

As compared with the upstream part of the Mekong River, the flood hydrology of the VMD is typically classified as having relatively low peaks but high volume. This behaviour is due to the effect of the natural Tonle Sap Lake, which is an important reservoir in the Mekong basin. The lake reduces the intensity of the upstream flood hydrograph by storing a part of flood flows and releasing gradually flows to downstream (MRC, 2007). An analysis of the annual floods of the last $50 \mathrm{yr}$ shows that every year flood lasts for several months and is characterised by discharges that are higher than $13600 \mathrm{~m}^{3} \mathrm{~s}^{-1}$, which is defined as a critical threshold (MRC, 2007) (Fig. 3b).

Studies on the VMD flood extent, impact and vulnerability need to consider the effects on local economies, which are in direct relation to the land use or the so called "agroecological" zones of the VMD (Delgado et al., 2010). The agro-ecological zones and the land use map of 2006 are represented in Fig. 4. It can be noticed that the VMD is mainly dominated by rice-based farming. Fruit gardens are mainly located along the Mekong branch and to some extent along the Bassac. In the Ca Mau Peninsula, the main land cover types are single rice crop, double-crop of single rice crop in combination with a single upland crop, and intensive shrimp farming. In this study the land cover pattern of 2006 (Fig. 4) was available and therefore used as a reference for further discussion about the impacts of future flooding on the agriculture in the VMD, and it could be stated that the analysis of flood inundation dynamics in this area is of the upmost importance (Dinh et al., 2012).

According to the 2009 evaluation of the Institute for Climate Change Research (RICC) of Can Tho University, the rice fields that would be flooded during the second half of the rice season by $20 \mathrm{~cm}$, continuously for 1 to 4 days, would be seriously damaged, resulting in a loss of 80 to $100 \%$ of the yield. The same study analyses what would be the effect on a rice farm, of one day of continuous inundation, by determining the flood inundation extent on the exposed rice areas. A solution to protect these rice farms could be the construction of temporary dikes by farmers. These dikes have to be approximately $20 \mathrm{~cm}$ higher than the field surface in order to cope with floods. In cases where the water level is more than $50 \mathrm{~cm}$ above the land surface, farmers cannot build sufficient dikes to protect the rice fields, and therefore the mentioned study identified the areas which are potentially seriously harmed by large floods. In case of floods occurring in the early stage of the rice season, even though the rice can stay for a longer time inundated (1 to 14 days) (DRAGON, 2009), the continuous flood would delay the land preparation process for the next farming season. The present study looks at the flood events of short duration, and aims to identify what would be the impact of these events on the agricultural activities in the area under projected climate change conditions. The identified thresholds of 20 and $50 \mathrm{~cm}$ are used to map the flood events and to determine the areas exposed to such flood depths.

\subsection{Climate change projections}

Mekong is highly populated and in continuous development. It has a basin development plan (BDP) that looks at hydropower development and irrigation needs for the next $100 \mathrm{yr}$. There is a series of dams, constructed or planned to be constructed, on the upstream part of the Mekong River. The operation of dams and their impact on the discharge of the Mekong River, in conjunction with future climate changes, were analysed by MRC in a study in which future flows on the Mekong River and Mekong delta are predicted taking into consideration the combination of the future climate changes and the projected BDP in the basin (Hoanh et al., 2010). The study predicts future flow in six scenario situations by making a combination between the BDP and the SLR at the East and West Seas, as it was predicted by the Vietnam Ministry of Nature and Environment. The operation of dams and their consequent impact on the Mekong flow is part of the MRC study and is not debated in this paper.

The present study considers the MRC predicted flow at the upstream boundary of the VMD in two specific situations:

1. prediction of flow due to climate changes, considering that the actual situation of the development in the 


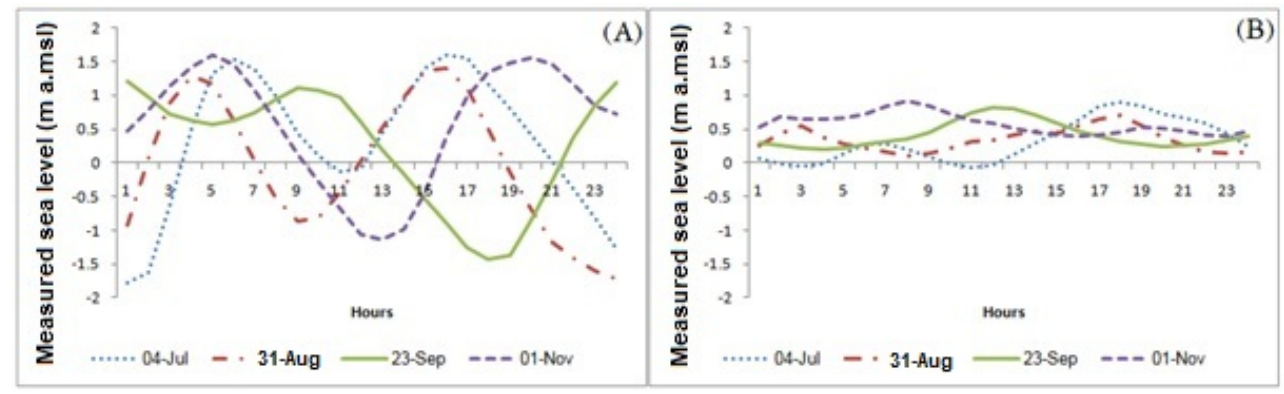

Fig. 2. Measured sea levels in the East (A) and West (B) Sea.

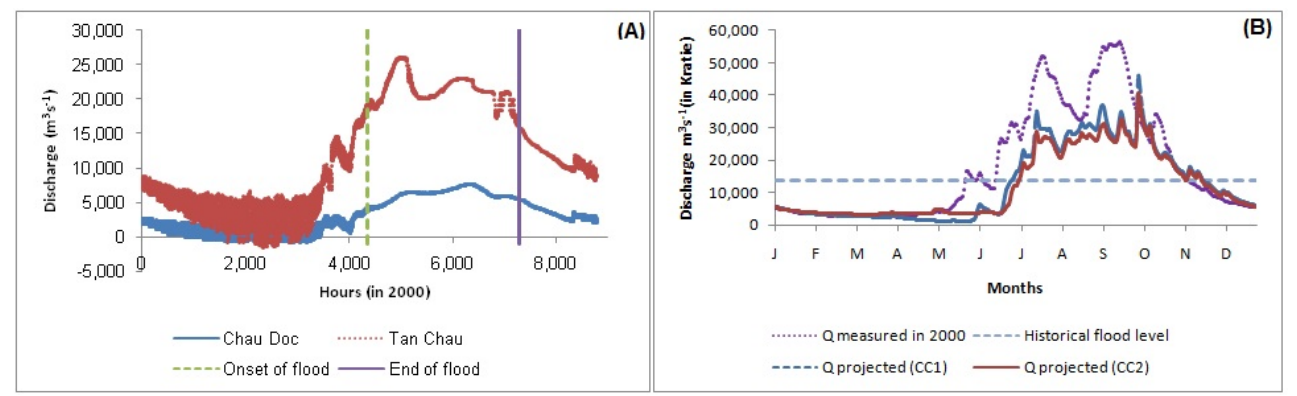

Fig. 3. Measured hourly discharge in 2000 at the Tan Chau and Chau Doc gauging stations (A); The annual hydrograph measured in 2000 , historical mean daily discharge (1985-2000) and projected annual hydrograph in 2050 (CC1 and CC2) (B).

basin will remain unchanged for the year 2050. In this scenario the assumption is that any basin development plans (i.e. hydropower development and irrigation) will take place after 2050. This case is denominated in the present paper as climate change situation $1(\mathrm{CC} 1)$;

2. prediction of flow due to climate changes, considering that the BDP will be implemented before the year 2050 . This case is denominated in the present paper as climate change situation 2 (CC2);

The discharge hydrographs at the upstream of the VMD at Kratie station are shown in Fig. 3b.

In cases where climate change scenarios $\mathrm{CC} 1$ and $\mathrm{CC} 2$ are applied, these flows will be affected; however, it is considered that they are still subject to the international treaties, and the projected upstream VMD discharge for the year 2050 is the one predicted by MRC studies.

According to the $\mathrm{CC} 1$ climate change projection, the Mekong River discharge is greater than the one of the $\mathrm{CC} 2$ projection, because with future developments (hydropower and irrigation) in the upstream Mekong basin, less water would arrive in the VMD. The baseline for the climate change projections was the available data on daily discharge from 1985 to 2000 (Hoanh et al., 2010). Analyses of this data show that, in comparison to the mean daily discharge (1985-2000), the projected flood in 2050 would start earlier in time and last for a longer period of time, e.g. will terminate later than the nowadays flood. If the threshold flood discharge of $Q_{\text {Kratie }}=13600 \mathrm{~m}^{3} \mathrm{~s}^{-1}$ (MRC, 2007) is considered as a base case, then the flood in 2050 would start 7 and 14 days earlier for the $\mathrm{CC} 1$ and $\mathrm{CC} 2$, respectively, and end approximately 14 days later. In general, the projected daily discharge during the flood period in the first projection would remain similar to the historical mean daily discharge, while the projected discharge in the second projection would be lower than the historical mean discharge.

\section{Model setup}

Many modelling studies were conducted in the VMD by local institutions, international consultants and researchers. A comprehensive overview of these models is given by Hoanh et al. (2010) and Johnson and Kummu (2011). Depending on the problem to be solved, or the objective of the study (e.g. design and planning), different software tools were used to build instantiated models of the VMD. The most used software tools are the Mike 11, Sobek, local Vietnam models, and ISIS 1-D, which are physically based models that solve the 1-D Saint Venant equations for shallow water flows in a river (network) with a mild slope.

The model used in the present study is the ISIS 1-D model of the VMD, which was developed by HR Wallingford and Halcrow, and is maintained by the Mekong River Commission (MRC). The model is used by MRC to study the impacts of climate change on the flow dynamics in the Mekong Delta. 
The results of the model are used by MRC to determine the boundary conditions for any detailed study of the Cambodian and Vietnamese Mekong Delta.

\section{The VMD model setup}

This study uses the hydrodynamic component of the ISIS 1D model and not the hydrological component. The hydrograph at the upstream boundaries is determined based on measured discharge and on predicted discharge as per the climate change scenarios $\mathrm{CC} 1$ and $\mathrm{CC} 2$. The predicted hydrograph of scenario $\mathrm{CC} 2$ is in accordance with the international agreements between the countries in which the Mekong basin is located.

The instantiated 1-D ISIS model of the VMD represents the whole Mekong delta (the Cambodian and the Vietnamese part of the delta together) using 3036 cross-sections for a $8619 \mathrm{~km}$ network of channels. The upstream boundary has 25 nodes and the downstream one has 19 nodes. The model also represents 193 spills, 528 junctions, 409 reservoirs, 749 floodplain units, and 29 sluices. This model is used by the MRC to determine the annual flood in the VMD. Because of the complexity of the whole VMD river network, the model includes the Cambodian part of the delta as well.

During the peak flood period, apart from the flows entering the VMD from the main rivers (through Tan Chau and Chau Doc), the overbank flows on the Cambodian part are especially important sources of inflows (Fujii, 2003; MRC, 2007). These inflows are represented as distributed lateral flows at the most upstream part of the VMD model. The ISIS model was developed to represent the complex interactions caused by tidal influences (along the East and West Seas), flow reversal in the Tonle Sap River and overbank flow in the flood season, with the varying inflows from upstream. Even though the ISIS model is considered to be able to provide a reasonable representation of the hydrodynamics of the Cambodian floodplain and VMD, MRC suggests that the model should not be used for design purposes (MRC, 2010b), but rather to estimate the trend of changes when the boundary conditions are modified. The reason for such advise is that, for such a large (deltaic) scale model, the lack of details for a specific area will lead to under- and/or over-estimation of the future events, and consequently wrong calculations of the planned construction.

The present study used the ISIS 1-D model in four simulation scenarios as follows:

a. Scenario 1: in which the initial set-up of the model was realised based on the flood data from the year 2000 (the 20 -yr return period of the annual flood volumes; MRC, 2007). The measured daily discharge at the Kratie gauging station was used as upstream boundary condition, and the hourly measured sea levels at East and West Seas were used as downstream boundary conditions.
Table 1. The setup of the model boundary conditions.

\begin{tabular}{lll}
\hline Models setup & Upstream boundary & Downstream boundary \\
\hline Scenario 1 & $\begin{array}{l}\text { Discharge hydrograph } \\
\text { of the year 2000 } \\
\text { Discharge hydrograph } \\
\text { of the year 2000 }\end{array}$ & $\begin{array}{l}\text { Sea water level in year 2000 } \\
\text { for both West and East Seas } \\
\text { Sea water level in year 2050 } \\
\text { (SL2000 + sea level rise) }\end{array}$ \\
Scenario 3a & $\begin{array}{l}\text { Projected discharge } \\
\text { of the year 2050 (CC1) }\end{array}$ & $\begin{array}{l}\text { Sea water level in year 2050 } \\
\text { (SL2000 + sea level rise) }\end{array}$ \\
Scenario 3b & $\begin{array}{l}\text { Projected discharge } \\
\text { of the year 2050 (CC2) }\end{array}$ & $\begin{array}{l}\text { Sea water level in year 2050 } \\
\text { (SL2000 + sea level rise) }\end{array}$ \\
\hline
\end{tabular}

b. Scenario 2: the simulation with no changes of the upstream discharge hydrograph, but with changes of the downstream boundary conditions, i.e. the projected sea level rise of up to $30 \mathrm{~cm}$ on both East and West Seas.

c. Scenario 3a: the simulation considering the projected upstream hydrograph, in accordance with the defined climate change scenarios $\mathrm{CC} 1$ and the projected SLR of 2050 (Fig. 3b).

d. Scenario $3 b$ : the simulation considering the projected upstream hydrograph, in accordance with the defined climate change scenarios CC2 and the projected SLR of 2050 .

The considered scenario descriptions (e.g. the boundary conditions, at both upstream and downstream ends of the hydrodynamic model) are summarised in Table 1.

For each scenario different simulations were carried out with regard to the downstream boundary conditions. The upstream discharge was maintained as the one projected to be valid for the climate change scenarios $\mathrm{CC} 1$ and $\mathrm{CC} 2$. A change of $\pm 30 \%$ and $\pm 15 \%$ of the projected sea level in 2050 has been applied in order to account for uncertainty of the sea level rise at the downstream end. The sensitivity analysis helped in identifying how the flood dynamics will affect the areas under consideration (rice farms, populated areas, etc.) for the year 2050 .

The results are presented for the upstream part of the delta, only in cases where the simulated flood depth is of $20 \mathrm{~cm}$ or more, because this is the established threshold for protection of rice farms. In the downstream part of the VMD, it was important to determine the areas where the time of inundation changed because of the effect this would have on timing of the two consecutive farming seasons.

\section{Results and discussions}

For each of the four scenarios, an analysis is done regarding the flood extent over the upstream and downstream section (i.e. the coastal areas) of the VMD. Due to the temporal distribution of the flood in the VMD, the spatial distribution of the flood on four different days is analysed. The days were selected based on historic flood records and are as follows: 


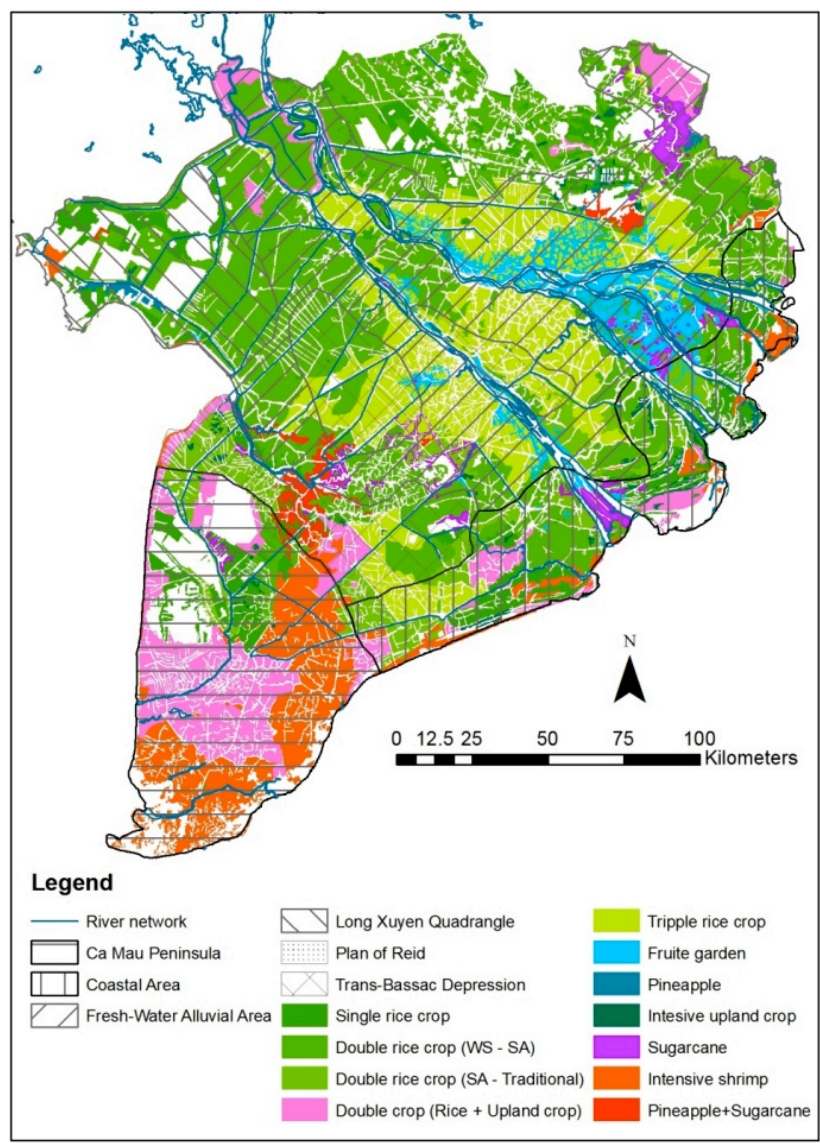

Fig. 4. Agro-ecological zones and land use map in the VMD in 2006.

- 4 July, the day of the early flood season when the flood starts causing damage on rice farming areas;

- 31 August, the day when the rice crop is, in general, harvested;

- 23 September, the day when the year 2000 flood peak was recorded (at Tan Chau and Chau Doc stations); and,

- 1 November, the day when the next rice farming season starts.

\subsection{Scenario 1: the calibration of the model with the 2000 yr flood event}

As a baseline case, the catastrophic flood of 2000 was considered, and simulated, and was used to calibrate the ISIS 1-D model. Figure 5 presents the maximum measured and simulated stages of one day during the flood period at different gauging stations (Tan Chau, Chau Doc, Vam Nao, My Thuan and Can Tho) in the VMD. The model overestimates the stage at all gauging stations. The maximum difference between the measured and simulated stage is $0.8,0.5,0.6$, 0.5 and $0.6 \mathrm{~m}$ at Tan Chau, Chau Doc, Vam Nao, My Thuan and Can Tho, respectively. The observed model errors are comparable to those observed in other studies: $0.3 \mathrm{~m}$ (Le et al., 2008); $1.1 \mathrm{~m}$ (Västilä et al., 2010); and, $0.2 \mathrm{~m}$ (Dung et al., 2011); and within the limit of errors for hydrodynamic models in cases of severe floods (Hartanto et al., 2011; Moya Quiroga et al., 2012; Quinn et al., 2010).

Spatial distribution of the flood in the upstream section on 4 July, 31 August, 23 September and 1 November in 2000 are presented in Fig. 6 where the water levels greater than 20 and $50 \mathrm{~cm}$ are shown. As the upstream discharge is gradually increasing from 4 July to 23 September, so is the flood extent. It can be noticed that the upstream discharge on 23 September is greater than the one on 1 November, however the flood extent is larger on 1 November. This phenomenon is caused by the fact that sea level on the East Sea is higher in November than in September (Fig. 2a and b); therefore, in addition to the flood impact there is a sea backwater effect as well. In addition, high tide on the East Sea is greater than on the West Sea, while low tides at the East Sea are lower than those on the West Sea. The outcome is that the East Sea tidal regime is the main driving force for the flood dynamics in the VMD (both spatially and temporally).

Figure 7 presents the inundated period (in hours) on the four considered dates. It can be seen that the further inland in the VMD, the longer the inundation time. For high values of the discharge at the upstream part of the VMD, the inundation area is extended towards the East Sea.

\subsection{Scenario 2: projected flooding due to SLR}

The results of the simulation, presented in Fig. 8, show the inundation time differences between scenario 1 and scenario 2 . The negative values are illustrating longer flood duration on 2050 as compared with the year 2000. The Ca Mau Peninsula is inundated a significantly longer time, about 4 months in total. This is due to the fact that this region is affected by the tidal regimes of the East and West Seas. The flood duration in the area along the West Sea is changed very little because there is no impact from the East Sea, and the Mekong and Bassac branches are routing the flood from inland to the East Sea.

\subsection{Scenario 3: projected flooding of 2050}

The results of the simulations under scenario $3 \mathrm{a}$ and scenario $3 \mathrm{~b}$ are presented separately for the upstream and downstream part of the VMD in order to identify the effect of the boundary conditions on the VMD.

Figures 9 and 10 present the inundation extent on the upstream section of the VMD on the four dates selected for analysis. The maps are showing inundation depths of 20 and $50 \mathrm{~cm}$ for the CC1 and CC2 scenarios, respectively. Similar to the simulated results of the flood extent in 2000, the flood extent in 2050 would increase from July to November. This is the effect of the backwater (as it is the case for the year 

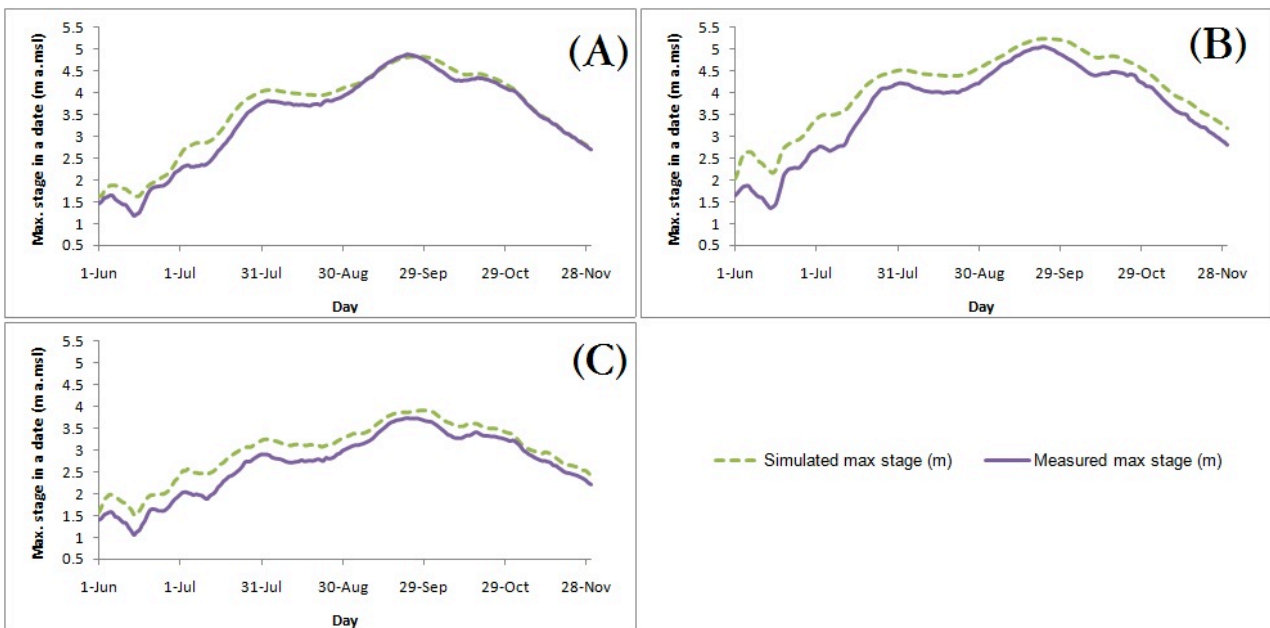

C)
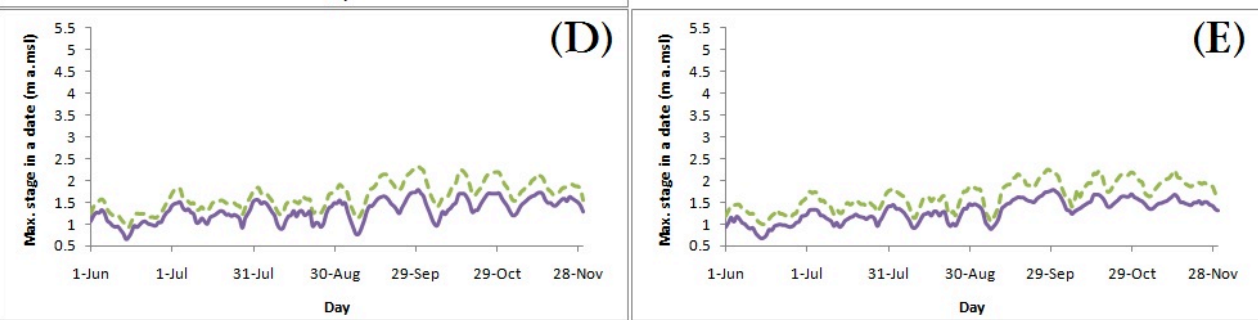

Fig. 5. Daily measured and simulated maximum stages during the flood period in 2000 at different gauging stations, (A) Chau Doc; (B) Tan Chau; (C) Vam Nao; (D) Can Tho; and, (E) My Thuan.

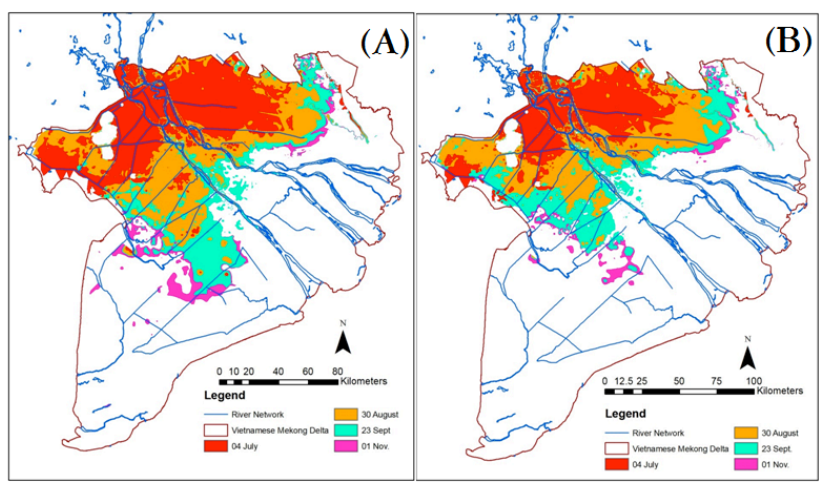

Fig. 6. Flood maps of year 2000, on 4 July, 31 August, 23 September and 1 November, inundation depth of $20 \mathrm{~cm}(\mathbf{A})$ and $50 \mathrm{~cm}(\mathbf{B})$.

2000), combined with the fact that the upstream hydrograph changed its pattern (e.g. the peak of the hydrograph shifted towards the end of October, Fig. 3b). In comparison to the simulated results in 2000, the inundated area in 2050 would extend further to the East Sea.

Figure 11 presents the flood extent for depths greater than $20 \mathrm{~cm}$ for the coastal area of the VMD according to scenario $3 \mathrm{a}$. The results of scenario $3 \mathrm{~b}$ show no change as compared with cenario $3 \mathrm{a}$. The flooding of the VMD remains mainly driven by the sea level rise along the East and West Seas, and the flood near the coastal area would be, as expected, greater in 2050. However, further inland the inundated area in 2050 would be smaller than the one in 2000, as the upstream discharge in 2050 would be lower than the one in 2000.

The flood on 2050 lasts longer along the coast, and shorter on the upstream section of the VMD (Fig. 12). In Fig. 12 the negative and positive values represent the longer and shorter flood durations in the year 2050 as compared with 2000.

The expected effects of longer inundation times in 2050 are the lower inundation depths. Figure 13 presents the differences between the simulated flood duration in 2050 according to the first and second projection; the positive value represents the longer flood duration in the first projection in comparison to the second one. Without development in the upstream section of the Mekong, the inundated period over the whole VMD could be extended from one day to about a month in total, in which the majority of increases would be around four days.

A similar analysis, as that for the $20 \mathrm{~cm}$ inundation depths in the year 2050, was done for inundation depths greater than $50 \mathrm{~cm}$. The analysis concluded that the flood in the coastal area was not affected strongly by the relatively small modification of the upstream discharges; in the early flood season (July) the flood that was affected by the tidal regime reached the upstream section of the VMD (up to Tan Chau and Chau Doc). However, with higher floods the inundated area that is impacted by tidal regimes went gradually sea-wards (from 


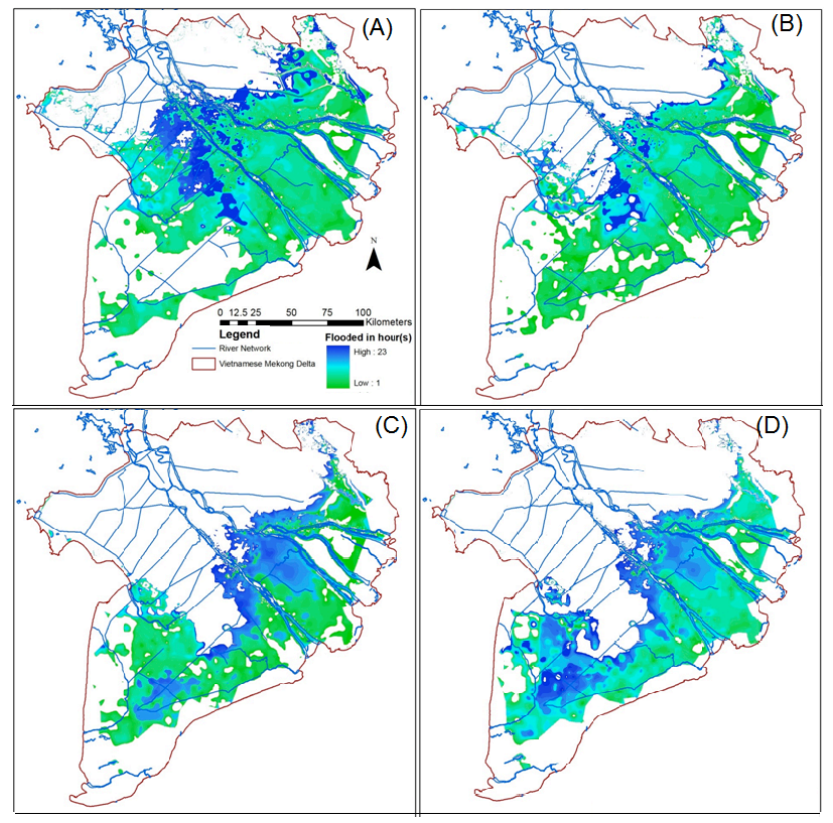

Fig. 7. The period of inundation (in hours) on 4 July (A), 31 August (B), 23 September (C) and 1 November (D) 2000.

July to November). In addition, due to the relatively poor drainage ability in the Ca Mau Peninsula, later in the flood season more permanent floods are projected; whereas the spatial distribution of flood patterns in the area surrounding the main outlets of the river network remained quite similar over the whole flood period.

\section{Discussions}

\subsection{Climate change and its impacts on the VMD}

When dealing with floods, studies on the impacts due to climate change should not consider the effect of a single event but the cummulatve impacts of combined events (e.g. upstream flood, local rainfall and high tide) (Keskinen et al., 2010). The impacts of climate change on the VMD should be addressed in different sections of the delta, such as the upstream vs. downstream (Gichamo et al., 2012; Quinn et al., 2010), the coastal zone vs. Ca Mau Peninsula and the east vs. west coast. The present study shows that in the Ca Mau Peninsula the flood is strongly influenced by both the East and West Seas; therefore, changes of the tidal regime in each sea will significantly change the future flood patterns. One of the main assumptions of the present study is the similarity of the changes of the sea level rise on the East and West Seas; hence, further study on this issue should be undertaken in order to make better projections for the future.

Within a small floodplain, a 1-D hydrodynamic model could result in acceptable accuracy in terms of simulated inundation extents and floodwave travel times (Hartanto et al., 2011). However, for a large river network with extensive

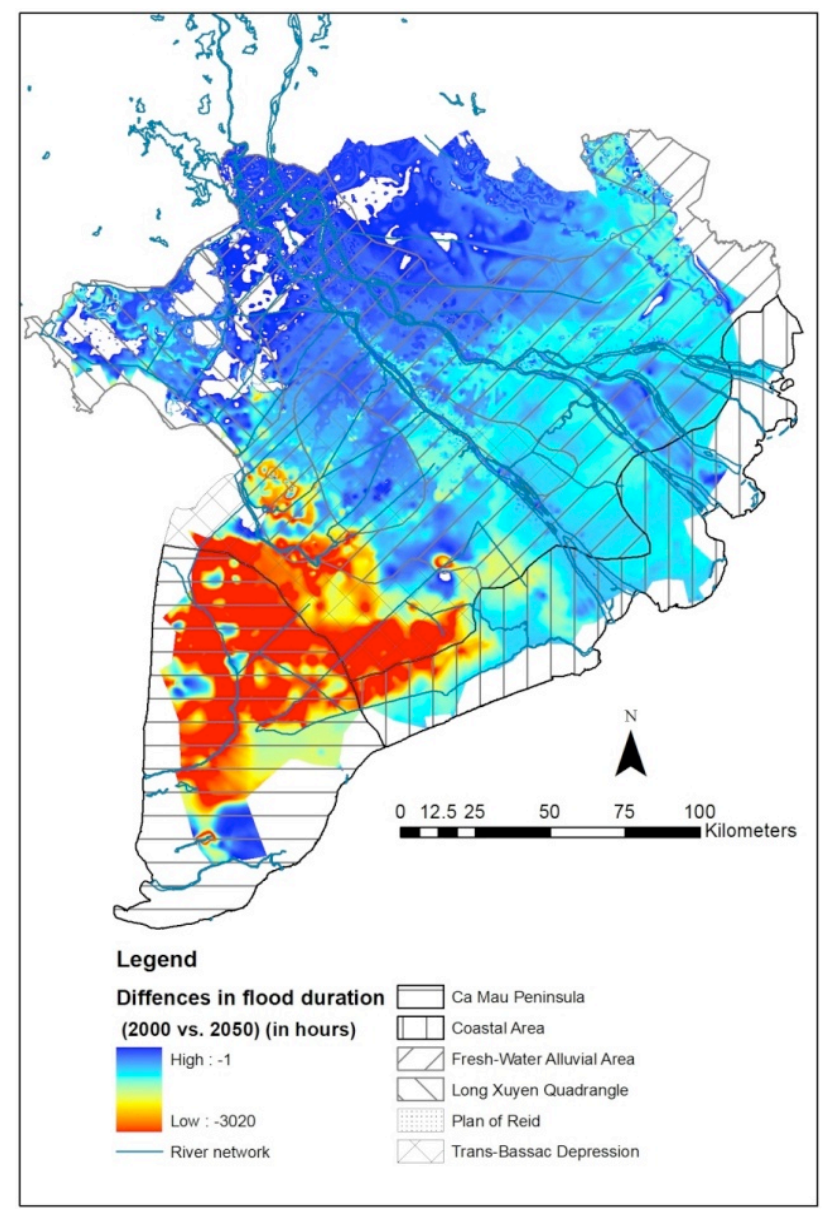

Fig. 8. Differences between the flood duration in 2000 and 2050 (CC2 2).

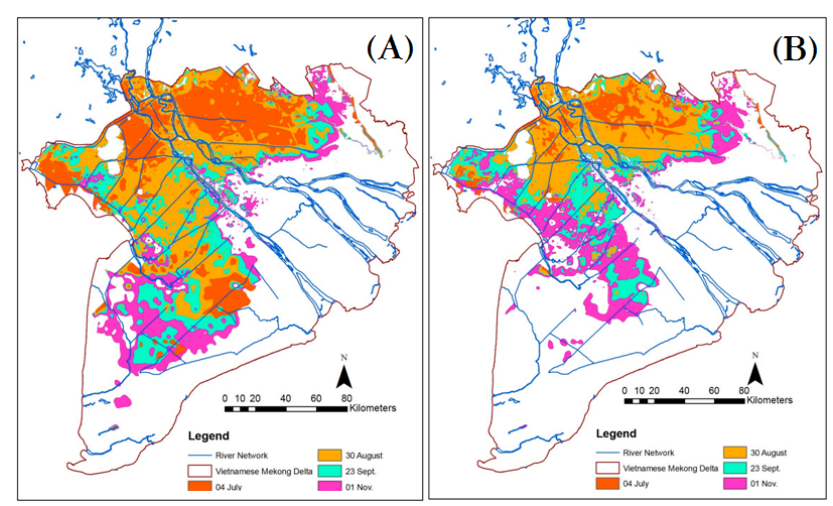

Fig. 9. The year 2050 flood maps, on 4 July, 31 August, 23 September and 1 November corresponding to the $\mathrm{CC} 1$ climate change scenario, for inundation depth of $20 \mathrm{~cm}(\mathbf{A})$ and $50 \mathrm{~cm}(\mathbf{B})$.

floodplain, 2-D hydrodynamic models were developed to study the detailed hydraulic nature rather than the mean conditions in a 1-D hydrodynamic model (Gichamo et al., 2012). Even though there were positive aspects of such 2-D 


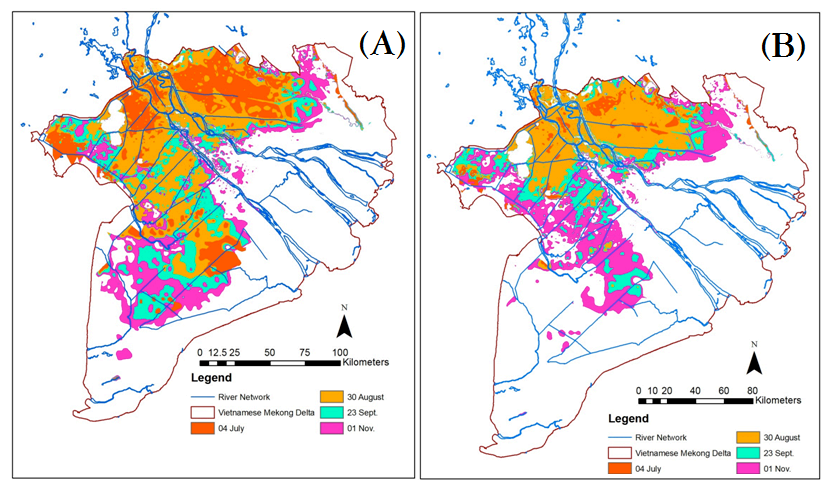

Fig. 10. The year 2050 flood maps, on 4 July, 31 August, 23 September and 1 November, corresponding to the $\mathrm{CC} 2$ climate change scenario, for inundation depth of $20 \mathrm{~cm}$ (A) and $50 \mathrm{~cm}$ (B).

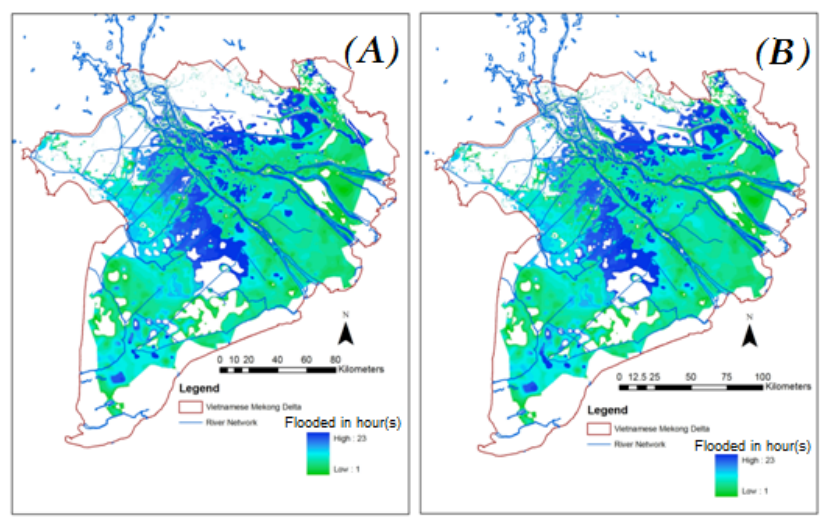

Fig. 11. The period of inundation (in hours) on 4 July, 2050 corresponding to $\mathrm{CC} 1(\mathbf{A})$ and $\mathrm{CC} 2(\mathbf{B})$.

hydrodynamic models, due to the computational requirements as well as the intensive data needs, they were not very popular for large river networks like the one in the VMD area. The complexity of the present ISIS 1-D model was constrained by the availability of data (e.g. detailed bathymetry), and therefore modelling of a complex river network is still a great challenge due to significant differences in the hydraulic nature along the river network (Costelloe et al., 2006; Dinh et al., 2012; Gichamo et al., 2012). It is suggested that a coupled 1-D/2-D or a full 2-D hydrodynamic model should be developed in the future in order to study the flow and its propagation along the floodplain. A detailed 2-D model can be used for specific studies such as flood risk assessments on a small scale (Dutta et al., 2007; Muste et al., 2010; Pender and Neelz, 2007; Balica et al., 2012).

The Mekong River in the VMD is characterized by fluvialunstable networks and the applied one-dimensional hydrodynamic model did not take into account the changes in river morphology. It is advisable that when the required data (e.g. sediment size) becomes available, a more comprehensive hydrodynamic model should be built in order to account for the changes of river morphology.

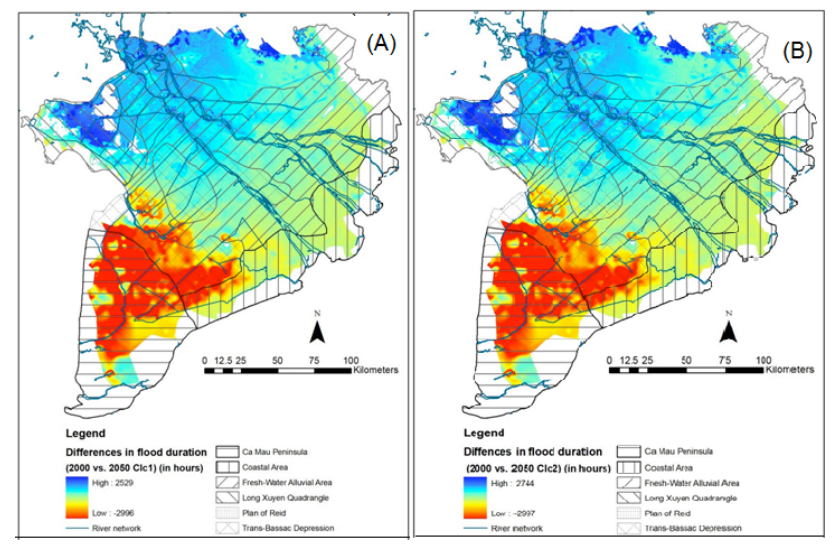

Fig. 12. Differences in flood durations in 2000 and 2050 corresponding to the climate change Scenario CC1 (A) and CC2 (B).

\subsection{Impacts of the flood on the agriculture in the VMD}

It is expected that the future climate changes will significantly impact the agricultural activities but it is difficult to quantitatively assess such influences (Dinh et al., 2012). Västilä et al. (2010) stated that the damage to crops and infrastructure in the VMD will be serious, as the average and maximum water levels and flood duration will increase in the period 2010-2049. The findings of the present research also support this argument. One may expect that with the rise of the sea level only the agricultural system (including the ricebased farming systems and shrimp farming) in the Ca Mau Peninsula will be strongly affected, while the deep flood extent in the upstream section does not change significantly as compared to the 2000 flood.

Because of changes to future annual hydrograph patterns, at the upstream section of the Mekong there will be considerable impacts on the flood extent and water level in the VMD. Consequently, these will lead to significant impacts on the agricultural activities. Moreover, because we could notice a forward in time shift of the flood season, the (rice) cropping activities need to be adjusted in order to avoid the predicted November flood. The timing issue of flooding is critical for agriculture, as can be concluded from the effects of the 2000 extreme flood which caused severe damage not only due to the high discharge and stage, but also due to its early arrival (4 to 6 weeks earlier in comparison to the normal flood) (A. T. Le et al., 2007).

Simulated results show that floods would extend further to the Ca Mau Peninsula with the sea level rise. In fact, with the dense river network in the coastal area and greater differences between the low and high peaks of the tidal regime in the East Sea (in comparison to the West Sea), the floods were routed to the East Sea faster than to the West Sea. In addition, the hydraulic regime in the Ca Mau Peninsula was complicated as it was influenced strongly by both the East and West Seas. 


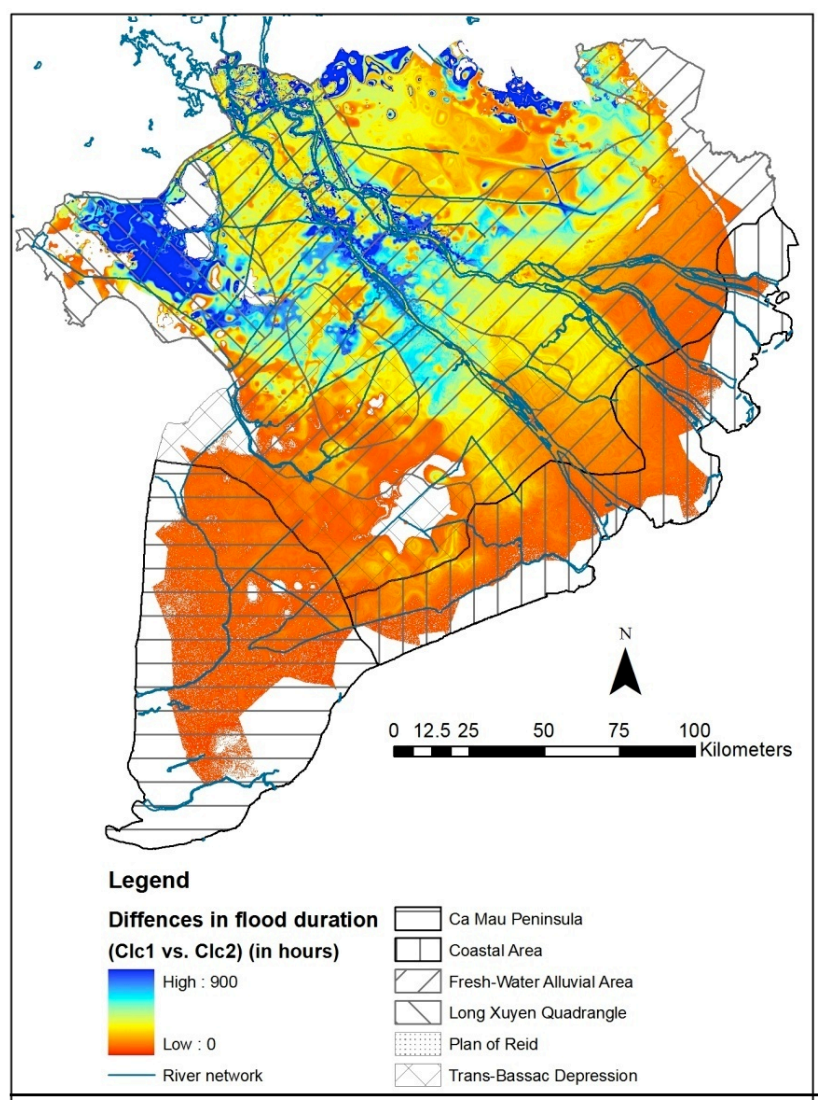

Fig. 13. Differences in flood durations in 2050 corresponding to the climate change scenarios $\mathrm{CC} 1$ and $\mathrm{CC} 2$.

In specific consideration to agriculture during the flood period in the VMD, agricultural activities in the upstream section of the VMD will benefit as the physical conditions will be more favourable for agriculture due to the "lower flood" conditions. However, along the coastal area, especially in the Ca Mau Peninsula, the flood would be prolonged, which might cause changes in the structure of the current farming systems.

Potential adaptation measures in the VMD, where agriculture is the main economic sector of development, climate change adaptation in agriculture is a point of great interest. With different policies to ensure the rice-based farming systems, permanent dikes along the upstream section of the VMD were raised to effectively protect the rice-based farming systems from the annual floods (Nguyen et al., 2007). However, with the drawbacks of such a permanent dike system (e.g. environmental pollution and degradation of soil fertility) (Nguyen et al., 2007), semi-dike systems (MRC/WUPFIN, 2006) in combination with water retention (Buijse et al., 2002; Hartanto et al., 2011; Hooijer et al., 2004; Meire et al., 2010; Platteeuw et al., 2010; Popescu et al., 2010) could be considered as a suitable solution to maintain the agricultural production in the VMD. Actually, in the past (decades ago), floods were kept in backswamp areas in order to not only supply freshwater flow in main canals during the early dry season (Dang et al., 2007), but also to reduce the flood during the peak periods. For the irrigated rice-based farming systems the possible adaptation measures might be applied in the VMD, including (i) adjusting the cropping seasons could be a suitable adaptation measure to avoid the peaks of the flood (ADB, 2010; Mainuddin and Kirby, 2009); (ii) shifting from rice intensification systems into livelihood diversification; (iii) alternating wetting and drying irrigation methods (Belder et al., 2004); and (iv) diversifying cropping patterns (Hoanh et al., 2009). Moreover, to study the nature of the future flood in the VMD, climate change aspects (upstream discharge changes and sea level rise) should not be considered separately from other factors (e.g. economic and social environment) (Keskinen et al., 2010). It is important to notice that the physical changes would normally not be happening so suddenly (e.g. sea level would rise gradually over several decades, Wassmann et al., 2004). However, the anthropological factors contribute significantly to dramatic changes, like the dam construction along the upstream section of the Mekong (Yang et al., 2006; Kummu and Varis, 2007; Kummu et al., 2010), and those should be considered carefully and seriously before any action is turned into practice. In fact, "adaptation to climate change should be integrated in social economic planning at all scales" (Quinn et al., 2010; Muste et al., 2010).

Actions in order to inform the stakeholders in the area about the effect of floods and the adaptation measures could include, along with the modelling and prediction of such events, the use of modern technologies such as mobile phones (Jonoski et al., 2012a, b; van der Berg and Poepscu, 2005).

\section{Conclusions}

Fluvial floods in the VMD can be categorized into two groups: (i) floods in the upstream section mainly affected by the upstream discharge; and (ii) floods in the coastal area strongly influenced by the East and West Sea tidal regimes.

Flood maps (in the upstream section and coastal areas in the VMD) were analysed for the most four critical dates in a flood season. For the highest recent flood in 2000 the affected areas were mainly in the upstream part of the delta. For the year 2050, the flood hazards are expected to be more severe along the coastal area because of the tidal regime (e.g. hightide induced fluvial floods, low tides allow drainage of the river flow to the sea).

It can be concluded that the future floods would have lower inundation depths but will last longer in the upstream section of the VMD. However, due to the change of the downstream boundary conditions (e.g. SLR), the inundated area along the Eastern and Western coasts, especially for the Ca Mau Peninsula, would be larger than the present one. Due to the dense 
river network in the coastal area and low sea level during the low tides, the flood duration in coastal area would not be long, and often will last less than $24 \mathrm{~h}$ even if the sea level rises.

Our analysis shows that in the future (year 2050), agriculture in the upstream section of the VMD may be expected to have more favourable conditions, as the fluvial flood would be shifted towards the lower part of the VMD. In the downstream section (along the coastal zone and the Ca Mau Peninsula), longer inundation times might be a good environment for rice cultivation. In fact, the high stage would be higher due to the projected increase of sea level but such floods would not last long due to the impacts of the tidal regime. However, as this study is on floods, we cannot draw definitive conclusions on the impacts of climate change and upstream development on rice cultivation, as changes in the water availability in the dry season have not been studied.

In the end the authors would like to emphasize that all results are based on the available model-based climate change projections, which are highly uncertain, and therefore the flood maps and the conclusions should be considered with care, as indicated throughout.

Acknowledgements. The research presented herein constitutes a part of the Post-doctoral Programme on Climate Change Adaptation in the Mekong River Basin (PRoACC) funded by the Netherlands Ministry of Development Cooperation (DGIS) through the UNESCO-IHE Partnership Research Fund. The study was carried out jointly by UNESCO-IHE Institute for Water Education, the Netherlands, and Can Tho University, Vietnam, with the participation of the Mekong River Commission. It has not been subjected to peer and/or policy review by the mentioned institutions, and, therefore, does not necessarily reflect the views of these institutions.

The authors would like to thank the Mekong River Commission (MRC) for kindly providing and allowing the use of the ISIS hydrodynamic model in order to carry out the study.

Edited by: A. Montanari

\section{References}

ADB: Technical Assistance ReportNam: Climate Change Impact and Adaptation Study in the Mekong Delta, 2009.

ADB: Addressing Climate Change in Asia and the Pacific: Priorities for Action, 2010.

Balica, S. F., Popescu, I., Beevers, L., and Wright, N. G.: Parametric and physically based modelling techniques for flood risk and vulnerability assessment: a comparison, Environ. Modell. Softw., doi:10.1016/j.envsoft.2012.11.002, in press, 2012.

Belder, P., Bouman, B. A. M, Cabangon, R., Guan, L., Quilang, E. J. P., Yuanhua, L., Spietz, J. H. J, and Tuong, T. P.: Effect of watersaving irrigation on rice yield and water use in typical lowland conditions in Asia, Agr. Water Manage., 65, 193-210, 2004.
Black, A. R. and Burns, J. C.: Re-assessing the flood risk in Scotland, Sci. Total Environ., 294, 169-184, 2002.

Buijse, A. D., Coops, H., Staras, M., Jans, L. H., Van Geest, G. J., Grift, R. E., Ibelings, B. W., Oosterberg, W., and Roozen, F. C. J. M.: Restoration strategies for river floodplains along large lowland rivers in Europe, Freshwater Biol., 47, 889-907, doi:10.1046/j.1365-2427.2002.00915.x, 2002.

Carew-Reid, J.: Rapid Assessment of the Extent and Impact of Sea Level Rise in Viet Nam, Climate Change Discussion Paper 1. Brisbane, Australia: ICEM - International Centre for Environmental Management, 2008.

Costelloe, J., Grayson, R., and McMahon, T.: Modelling streamflow in a large anastomosing river of the arid zone, Diamantina River, Australia, J. Hydrol., 323, 138-153, 2006.

Dang, K. N., Nguyen, V. B., and Nguyen, H. T.: Water use and competition in the Mekong Delta, Vietnam, Proceedings to Challenges to sustainable development in the Mekong Delta: Resional and national policy issues and research needs, 143-188, 2007.

Delgado, J. M., Apel, H., and Merz, B.: Flood trends and variability in the Mekong river, Hydrol. Earth Syst. Sci., 14, 407-418, doi:10.5194/hess-14-407-2010, 2010.

Dinh, N. Q., Balica, S., Popescu, I., and Jonoski, A.: Climate change impact on flood hazard, vulnerability and risk of the Long Xuyen Quadrangle in the Mekong Delta, International Journal of River Basin Management, 10, 103-120, 2012.

Dooge, J. C. I. and Napiorkowski, J. J.: The effect of the downstream boundary conditions in the linearized St. Venant Equations, Mech. Appl. Math, 40, 245-256, 1987.

DRAGON: Institute Vietnam, Climate change impacts and vulnerabilities assessment for Can Tho City (Technical report), Can Tho, 2009.

Dung, N. V., Merz, B., Bárdossy, A., Thang, T. D., and Apel, H.: Multi-objective automatic calibration of hydrodynamic models utilizing inundation maps and gauge data, Hydrol. Earth Syst. Sci., 15, 1339-1354, doi:10.5194/hess-15-1339-2011, 2011.

Dutta, D., Alam, J., Umeda, K., Hayashi, M., and Hironaka, S.: A two-dimensional hydrodynamic model for flood inundation simulation: a case study in the lower Mekong river basin, Hydrol. Process., 21, 1223-1237, 2007.

Ericson, J. ,Vorosmarty, C., Dingman, S.. Ward, L., and Meybeck, M.: Effective sea-level rise and deltas: Causes of change and human dimension implications, Global Planet. Change, 50, 63-82, 2006.

Fujii, H.: Hydrological roles of the Cambodian floodplain of the Mekong River, J. River Basin Management, 1, 253-266, 2003.

Gichamo, Z. G., Popescu, I., Jonoski, A., and Solomatine, D. P.: River Cross Section Extraction from ASTER Global DEM for Flood Modeling, Environ. Modell. Softw., 31, 37-46, 2012.

Gupta, A., Lim, H., Huang, X., and Chen, P.: Evaluation of part of the Mekong River using satellite imagery, Geomorphology, 44, 221-239, 2002.

Hartanto, I. M., Beevers, L., Popescu, I., and Wright, N. G.: Application of a coastal modelling code in fluvial environments, J. of Environmental Modelling and Software, 26, 1685-1695, 2011.

Hoanh, C. T., Phong, N. D., Gowing, J. W., Tuong, T. P., Ngoc, N. V., and Hien, N. X.: Hydraulic and water quality modeling: a tool for managing land use conflicts in inland coastal zones, Water Policy, 11, 106-120, 2009. 
Hoanh, C. T., Jirayoot, K., Lacombe, G., and Srinetr, V.: Impacts of climate change and development on Mekong fow regime. First assessment - 2009, MRC Technical Paper No. 29, Mekong River Commission, Vientiane, Lao PDR, 2010.

Hooijer, A., Klijn, F., Bas , G., Pedroli, M., and Van Os, A.: Towards sustainable flood risk management in the Rhine and Meuse river basins: synopsis of the findings of IRMA-SPONGE, River Res. Appl., 20, 343-357, 2004.

Johnston, R. and Kummu, M.: Water Resource Models in the Mekong Basin: A Review, Water Resour. Manage., 26, 429-455, 2011.

Jonoski, A., Alfonso, L., Almoradie, A., Popescu, I., van Andel, S. J., and Vojinovic, Z.: Mobile phone applications in the water domain, Environ. Eng. Manag. J., 11, 919-930, 2012a.

Jonoski, A., Almoradie, A., Khan, K., Popescu, I., and Andel, S. J.: Google Android Mobile Phone Applications for Water Quality Information Management, J. Hydroinform., doi:10.2166/hydro.2012.147, in press, 2012b.

Keskinen, M., Chinvanno, S., Kummu, M., Nuorteva, P., Snidvongs, A., Varis, O., and Vastila, K.: Climate change and water resources in the Lower Mekong River Basin: putting adaptation into the context, Journal of Water and Climate Change, 1, 103-117, 2010.

Kummu, M. and Varis, O.: Sediment-related impacts due to upstream reservoir trapping, the Lower Mekong River, Geomorphology, 85, 275-293, 2007.

Kummu, M., Lu, X., Wang, J., and Varis, O.: Basin-wide sediment trapping efficiency of emerging reservoirs along the Mekong, Geomorphology, 119, 181-197, 2010.

Le, A. T., Chu, T. H., Miller, F., and Bach, T. S.: Flood and salinity management in the Mekong Delta, Vietnam, in: Challenges to sustainable development in the Mekong Delta: Resional and national policy issues and research needs, edited by: Tran, T. B., Bach, T. S., and Miller, F., 2007.

Le, T. V. H., Nguyen, H. N., Wolanski, E., Tran, T. C., and Haruyama, S.: The combined impact on the flooding in Vietnam's Mekong River delta of local man-made structures, sea level rise, and dams upstream in the river catchment, Estuar. Coast. Shelf S., 71 110-116, 2007.

Le, T. V. H, Shigeko, H., Nguyen, N. H., and Tran, T. C.: Infrastructure effects on floods in the Mekong River Delta in Vietnam Area, Hydrol. Process., 22, 1359-1372, 2008.

Lespinas, F., Ludwig, W., and Heussner, S.: Impact of recent climate change on the hydrology of coastal Mediterranean rivers in Southern France, Climatic Change, 99, 425-456, 2009.

Lu, X. X. and Siew, R. Y.: Water discharge and sediment flux changes over the past decades in the Lower Mekong River: possible impacts of the Chinese dams, Hydrol. Earth Syst. Sci., 10, 181-195, doi:10.5194/hess-10-181-2006, 2006.

Mainuddin, M. and Kirby, M.: Spatial and temporal trends of water productivity in the lower Mekong river, Agr. Water Manage., 96, 1567-1578, 2009.

Meire, D., De Donker, L., Declercq, F., Buis, K., Troch, P., and Verhoeven, R.: Modelling river-floodplain interaction during flood propagation, Nat. Hazards, 55, 111-121, 2010.

Moya Quiroga, V., Popescu, I., Solomatine, D., and Bociort, L.: Cloud and cluster computing in uncertainty analysis of integrated flood models, J. Hydroinform., 15, 55-69, doi:10.2166/hydro.2012.017, 2012.

MRC: Annual Mekong Flood Report 2006, Vientiane, Laos, 2007.
MRC: Annual Mekong Flood Report 2009, Phnom Penh, Cambodia, 2010a.

MRC: Improved flood risk reduction through implementation of structural measures flood proofing, 2010b.

MRC/WUP-FIN: Hydrological, environmental and socio-economic modelling tools for the Lower Mekong Basin impact assessment - Mekong Delta socio-economic analysis, WUP-FIN Phase II - Hydrological, environmental and socio-economic modelling tools for the Lower Mekong Bas. Vientiane, Lao PDR, 2006.

Muste, M., Quinn, P. F., Hewett, C. J. M., Popescu, I., Basu, N. B., Kumar, P., Franz, K., Merwade, V., Arnold, W., and Potter, K.: Initiation of the Upper Mississippi River Basin Observatory, ASCE proceedings, Innovations in Watershed Management under Land Use and Climate Change, 39, 1270-1281, 2010.

Neuhold, C., Stanzel, P., and Nachtnebel, H. P.: Incorporating river morphological changes to flood risk assessment: uncertainties, methodology and application, Nat. Hazards Earth Syst. Sci., 9, 789-799, doi:10.5194/nhess-9-789-2009, 2009.

Nguyen, A. D. and Savenije, H. H. : Salt intrusion in multi-channel estuaries: a case study in the Mekong Delta, Vietnam, Hydrol. Earth Syst. Sci., 10, 743-754, doi:10.5194/hess-10-743-2006, 2006.

Nguyen, D. C., Le, T. D., Nguyen, V. S., and Miller, F.: Chapter 2: Livelihoods and resource use stratefies of farmers in the Mekong Delta, in: Challenges to sustainable development in the Mekong Delta: Resional and national policy issues and research needs, 69-98, 2007.

Nuorteva, P., Keskinen, M., and Varis, O.: Water, livelihoods and climate change adaptation in the Tonle Sap Lake area, Cambodia: learning from the past to understand the future, Journal of Water and Climate Change, 1, 87-101, 2010.

Pender, G. and Neelz, S.: Use of computer models of flood inundation to facilitate communication in flood risk management, Environmental Hazards, 7, 106-114, 2007.

Platteeuw, M., Foppen, R., and van Eerden, M. R.: The need for future wetland bird studies: Scales of habitat use as input for ecological restoration and spatial water management, Ardea, 98, 403-416, 2010.

Popescu, I., Jonoski, A., van Andel, S. J., Onyari, E., and Moya Quiroga, V. G.: Integrated modelling for flood risk mitigation in Romania: case study of the Timis-Bega river basin, International Journal of River Basin Management, 8, 269-280, 2010.

Prudhomme, C., Jakob, D., and Svensson, C.: Uncertainty and climate change impact on the flood regime of small UK catchments, J. Hydrol., 277, 1-23, 2003.

Quinn, P., Hewett, C., Popescu, I., and Muste, M.: Towards New Types of Water-centric Collaboration: Instigating the Upper Mississippi River Basin Observatory Process, Water Management, 163, 39-51, 2010.

Reichel, G. and Nachtnebel, H. P.: Suspended sediment monitoring in a fluvial environment: Advantage and limitations applying an acoustic doppler current, Water Research, 28, 751-761, 1994.

Västilä, K., Kummu, M., Sangmanee, C., and Chinvanno, S.: Modelling climate change impacts on the flood pulse in the Lower Mekong floodplains, Journal of Water and Climate Change, 1, 67-86, 2010.

van der Berg, C. C. and Popescu, I.: An experience in knowledge mapping, Journal of Knowledge Management, 9, 123-128, 2005. 
Wassmann, R., Nguyen, X. H., Chu, T. H., and To, P. T.: Sea level rise affecting the Vietnamese Mekong Delta: Water elevation in the flood season and implications for rice production, Climatic Change, 66, 89-107, 2004.

WWF: The Greater Mekong and climate change: Biodiversity, ecosystem services and development at risk, 2009.
Yang, Z., Wang, H., Saito, Y., Milliman, D., Xu, K., Quiao, S., and Shi, G.: Dam impacts on the Changjiang (Yangtze) River sediment discharge to the sea: The past 55 years and after the Three Gorges Dam, Water Resour. Res., 42, W04407, doi:10.1029/2005WR003970, 2006. 